\title{
REVIEW \\ Chemodenervation for treatment of limb spasticity following spinal cord injury: a systematic review
}

\author{
$\mathrm{J} \mathrm{Lui}^{1}{ }^{1}, \mathrm{M}$ Sarai $^{1}$ and PB Mills ${ }^{1,2,3,4}$
}

Study design: Systematic review.

Objectives: To systematically review the literature on chemodenervation with botulinum toxin (BoNT) or phenol/alcohol for treatment of limb spasticity following spinal cord injury (SCI).

Setting: British Columbia, Canada.

Methods: EMBASE, MEDLINE, CINAHL, Cochrane Database of Systematic Reviews and Cochrane Central Register of Controlled Trials were searched for English language studies published up until March 2014. Studies were assessed for eligibility and quality by two independent reviewers.

Results: No controlled trials were identified. A total of 19 studies were included: 9 involving BoNT and 10 involving phenol/alcohol. Owing to the clinically diverse nature of the studies, meta-analysis was deemed inappropriate. The studies produced level 4 and level 5 evidence that chemodenervation with BoNT or alcohol/phenol can lead to improvement in outcome measurements classified in the body structure and function, as well as activity domains of the International Classification of Functioning, Disability and Health framework. The Modified Ashworth Scale (MAS) was the most commonly used outcome measure. All six studies on BoNT and three of the four studies on phenol/alcohol measuring MAS reported a decrease in at least one point. An improvement in MAS was not always associated with improvement in function. The effect of phenol/alcohol has the potential to last beyond 6 months; study follow-up did not occur beyond this time point.

Conclusion Chemodenervation with BoNT or phenol/alcohol may improve spasticity and function in individuals with SCl. However, there is a lack of high-quality evidence and further research is needed to confirm the efficacy of these interventions.

Spinal Cord (2015) 53, 252-264; doi:10.1038/sc.2014.241; published online 13 January 2015

\section{INTRODUCTION}

Although precise definitions vary, spasticity is commonly cited as 'a motor disorder characterized by a velocity dependent increase in tonic stretch reflexes (muscle tone) with exaggerated tendon jerks, resulting from hyper-excitability of the stretch reflexes, as one component of the upper motor neuron syndrome.. ${ }^{1}$ Spasticity frequently occurs following damage to the central nervous system, such as spinal cord injury (SCI). Literature has shown that $53-78 \%$ of individuals with chronic SCI experience symptoms of spasticity. ${ }^{2,3}$ Importantly, $27-40 \%$ of affected individuals consider spasticity to be problematic and associated with significant functional impairments. ${ }^{4,5}$ The negative impacts of limb spasticity include restricted ability to carry out activities of daily living, inhibition of functional ambulation, pain, fatigue, increased risk of developing contractures and pressure sores and difficulties with self-hygiene. ${ }^{2}$ Spasticity can be a major barrier to participation and employment ${ }^{6}$ and is negatively associated with quality of life ${ }^{7}$ following SCI.

Generally, limb spasticity is managed through a multimodal approach, which may include physical interventions (for example, stretching, bracing and muscle strengthening), anti-spasticity medications (for example, delivered orally, via injection to the muscles/nerves, or intrathecally) and surgery. Oral antispasticity medications are often prescribed to SCI patients; however, the effectiveness of these medications varies and may be limited by systemic side effects including sedation, confusion, hallucinations, nausea, generalized muscle weakness, hypotension and potential liver toxicity. ${ }^{8}$ It is estimated that up to $40 \%$ of patients with spasticity are unable to tolerate the side effects of oral antispasticity agents. ${ }^{9}$ Chemodenervation is an attractive option for the management of limb spasticity, as it is a local injection technique that may be used to manage focal muscle overactivity while minimizing systemic side effects. Commonly used chemodenervation agents include botulinum toxin (BoNT), phenol and alcohol..$^{10}$ The utility of phenol has been reported in the literature for over 5 decades, ${ }^{11}$ whereas the utility of alcohol and BoNT has been demonstrated more recently.

Various systematic reviews have examined the safety and efficacy of chemodenervation for managing spasticity in stroke $\mathrm{e}^{12,13}$ and cerebral palsy. ${ }^{14,15}$ However, no such review exists for SCI. Although studies on stroke and cerebral palsy have consistently shown that BoNT can reduce muscle tone and spasticity, its effect on functional outcomes is

${ }^{1}$ International Collaboration on Repair Discoveries (ICORD), Faculty of Medicine, University of British Columbia, Vancouver, British Columbia, Canada; ${ }^{2}$ Division of Physical Medicine and Rehabilitation, Faculty of Medicine, University of British Columbia, Vancouver, British Columbia, Canada; ${ }^{3}$ GF Strong Rehabilitation Center, Vancouver Coastal Health, Vancouver, British Columbia, Canada and ${ }^{4}$ Rehabilitation Research Program, Vancouver Coastal Health Research Institute, Vancouver, British Columbia, Canada Correspondence: Dr PB Mills, Division of Physical Medicine and Rehabilitation, International Collaboration on Repair Discoveries (ICORD), Faculty of Medicine, University of British Columbia, 818 West 10th Avenue, Vancouver, British Columbia, Canada V5Z 1 M9.

E-mail: patricia.mills@vch.ca

Received 16 October 2014; revised 28 November 2014; accepted 3 December 2014; published online 13 January 2015 
less certain. ${ }^{16}$ Furthermore, spasticity patterns may differ according to whether a lesion occurs in the brain or at the level of the spinal cord. ${ }^{17}$ For example, muscle synergy and spasticity induce distinctive and complex movement patterns in individuals with stroke primarily characterized by spastic hemiplegic posturing, ${ }^{18}$ whereas extensor spasms, flexor withdrawal spasms and clonus are frequently reported in SCI. ${ }^{19}$ Different patterns can impact the functional sequelae of the spasticity, ${ }^{19}$ and consideration of these patterns may improve the dosing, goal setting and outcome measures selected to examine the effects of spasticity treatment. Therefore, it is important to consider population-specific outcomes when examining the benefit of an intervention such as chemodenervation.

The objective of this systematic review is to provide clinicians with evidence regarding the efficacy of chemodenervation with either BoNT or phenol/alcohol for the management of limb spasticity in SCI. In addition, identifying gaps in the evidence will allow researchers to direct future efforts to areas of priority.

\section{PATIENTS AND METHODS}

\section{Literature search}

A systematic literature search was conducted in EMBASE, MEDLINE, CINAHL, Cochrane Database of Systematic Reviews and Cochrane Central Register of Controlled Trials electronic databases up to March 2014. Librarians at the Royal College of Physicians and Surgeons of British Columbia developed search strategies. The search strategy for MEDLINE is described in the Appendix. Reference lists of reviews and relevant studies were retrieved and scanned for citations to expand the data set.

\section{Selection criteria}

Inclusion criteria for studies were as follows: (1) study population of adults $(\geqslant 18$ years) with SCI and limb spasticity; (2) if the study involved participants with spasticity from different etiologies, at least $50 \%$ must have SCI; (3) intervention of chemodenervation with either BoNT, phenol or alcohol injected into one or more limbs; and (4) English language and available as a full-text article. Studies were excluded if chemodenervation was used to treat conditions other than upper or lower limb spasticity.

\section{Study selection}

Two independent reviewers (JL and MS) screened study titles and abstracts for eligibility. If eligibility remained unclear, the full article was reviewed. Any disagreement was resolved by consulting a third reviewer (PM).

\section{Risk of bias assessment}

It was determined a priori that quality assessment would be performed using the Physiotherapy Evidence Database (PEDro) ${ }^{20}$ scoring system for randomized controlled trials (RCTs) and the Downs and Black ${ }^{21}$ tool for non-RCTs. All other study designs would be deemed low quality, with levels of evidence described by Sackett et al. ${ }^{22}$ used to draw conclusions about the level of evidence for the identified studies. As previously described in the literature, Sackett's ${ }^{22}$ levels of evidence were collapsed into five categories, whereby evidence was rated level 1 if derived from good to excellent RCTs with PEDro scores of $\geqslant 6$, level 2 if derived from RCTs with PEDro scores of $\leqslant 5$ or from nonrandomized prospective controlled and cohort studies, level 3 if derived from case-control studies, level 4 if derived from either pre-test/post studies or case series, and level 5 if obtained from an observational report or case report involving a single subject or from clinical consensus. ${ }^{23}$

\section{Data extraction}

A customized excel spreadsheet was developed with a template adapted from the Cochrane Collaboration. ${ }^{24}$ Data were extracted by two reviewers (JL and MS) and reviewed in duplicate by another (PM). Data extracted included sample size, subject characteristics, injection details, outcome measures used and results, as well as adverse events. If study data were missing, or if subject level data were desired, two attempts separated by two weeks were made to contact the corresponding authors.

The International Classification of Functioning, Disability and Health ${ }^{25}$ (ICF) was published by the World Health Organization in May 2001 to provide a common international language for describing health and disability in clinical and research settings. The ICF framework classifies function in four domains: body structure and function, activity, participation and environmental/personal factors domains. Outcome measures from the studies included in this review were listed and classified according to ICF domains. Outcome measures that did not fit within a domain were classified as 'other'.

\section{Statistical analyses}

Because of a large variation in participant characteristics (for example, site of spasticity and degree of spasticity) and study methods (for example, dosing, injection techniques, follow-up periods and outcome measurements) among the included studies, a formal meta-analysis was not feasible. Therefore, the results of this review are presented in a narrative form. Description of outcome measures is presented in Table 1. The effectiveness of each intervention is outlined in Tables 2 and 3.

\section{RESULTS}

\section{Search strategy}

The electronic database search yielded 415 articles, 58 of which were duplicates (Figure 1). An additional 13 articles were added with scanning of reference lists. Upon review of titles and abstracts, 58 articles remained for detailed examination. A total of 19 articles were included in this review after inclusion criteria were applied.

\section{Studies}

Nine studies investigated the use of BoNT, ${ }^{26-34}$ and 10 studies investigated phenol/alcohol ${ }^{35-44}$ for management of spasticity in SCI with chemodenervation. The literature search did not identify any randomized or non-RCTs looking at management of spasticity in a sample population with $\geqslant 50 \%$ SCI participants, precluding the use of PEDro and Downs and Black Scale for quality assessment. One RCT by Richardson et al. ${ }^{45}$ had 6 out of 52 participants with SCI; however, we were unable to obtain participant level data; therefore, this study was excluded. All included studies were non-blinded; risk of bias was therefore high for all included studies. None of the studies were adequately powered.

\section{Description of outcome measures}

A total of 43 distinctive outcome measures were used within the studies (Table 1). In all, 25 measurements were classified in the ICF body structure and function domain, 15 in the activity domain, none in the participation and environmental/personal factors domain and three did not fit within one of the four domains. No studies used an outcome measurement that measured quality of life. The most commonly used outcome measure was the MAS $(n=10)$.

\section{Chemodenervation with BoNT}

BoNT is injected into spastic muscles to cause weakness via blockade of the neuromuscular junction. The toxin is internalized by the presynaptic motor neuron, where it inhibits the release of acetylcholine by disrupting the function of the SNARE complex, which is required for the exocytosis of presynaptic vesicles. ${ }^{2}$ Two serotypes of BoNT exist for use in spasticity management: Type A (for example, Botox, Dysport, Xeomin) and Type B (Myobloc). Mechanistically, these differ in terms of where they bind on the SNARE complex. ${ }^{46}$ However, the end result is the same-acetylcholine is not released, neuromuscular transmission is inhibited and muscle paresis occurs. Clinically, the effect of BoNT can last 2-6 months. With time, 
Table 1 Description of outcome measures

\begin{tabular}{|c|c|c|}
\hline Outcome measure & $\begin{array}{l}\text { BoNT } \\
\text { studies }\end{array}$ & $\begin{array}{c}\text { Phenol/alcohol } \\
\text { studies }\end{array}$ \\
\hline \multicolumn{3}{|l|}{ Structure/function } \\
\hline MAS & 6 & 4 \\
\hline Pain VAS & 3 & 3 \\
\hline Spasm frequency score & 3 & 1 \\
\hline MRC for strength & 1 & 1 \\
\hline AS & 1 & 1 \\
\hline Quadriceps peak voluntary isokinetic torque & 1 & - \\
\hline Stretch-reflex angle at peak torque & 1 & - \\
\hline MTS grade+angle & 1 & - \\
\hline Peak knee flexion & 1 & - \\
\hline Muscle balance score & 1 & - \\
\hline Toe clawing VAS & 1 & - \\
\hline EPUAP & 1 & - \\
\hline ROM scale of passive abduction of hip joint & - & 1 \\
\hline Passive ROM of shoulder joint & - & 1 \\
\hline Active ROM of shoulder joint & - & 1 \\
\hline Muscle spasm score: degree of adductor tone & - & 1 \\
\hline Buttock seat interface pressure & - & 1 \\
\hline ROM of hip joint & - & 1 \\
\hline Hip extension angle-prone & - & 1 \\
\hline Hip extension angle with mundale technique & - & 1 \\
\hline \multicolumn{3}{|l|}{ Activity } \\
\hline $\begin{array}{l}\text { Gait analysis (velocity; stride length; cadence; } \\
\text { swing phase\%) }\end{array}$ & 6 & - \\
\hline$\%$ functional improvement (participant report) & 2 & - \\
\hline Hygiene score & - & 2 \\
\hline Timed stair climbing test & 1 & - \\
\hline 6-min walk test & 1 & - \\
\hline VRS-Gait Function discomfort with walking & 1 & - \\
\hline Modified rivermead mobility index & 1 & - \\
\hline Repty functional index & 1 & - \\
\hline Functional ambulatory category & 1 & - \\
\hline Hospital de Sagunto Gait Scale & 1 & - \\
\hline Timed walking over $20 \mathrm{~m}$ & 1 & - \\
\hline Gait scale & - & 1 \\
\hline Eating item of functional independence measure & - & 1 \\
\hline Hygiene score & - & 1 \\
\hline ADL (self reported improvement) & - & 1 \\
\hline \multicolumn{3}{|l|}{ Other } \\
\hline Modified FACES scale for satisfaction & 1 & - \\
\hline Antispasticity medication dose & 1 & - \\
\hline Subjective spasticity evaluation & 1 & - \\
\hline
\end{tabular}

Abbreviations: ADL, activities of daily living; EPUAP, European Pressure Ulcer Advisory Panel Classification system; MRC, Medical Research Council Scale; MTS, Modified Tardieu Scale; ROM, range of motion; VRS, Verbal Rating Scale.

collateral sprouting and regrowth of nerve endings will reverse the effects of BoNT.

The effects of BoNT on individuals with SCI were reported in three level 4 pre-post studies ${ }^{26-28}$ and six level 5 studies (one retrospective chart review, ${ }^{29}$ five case series/studies ${ }^{30-34}$ ). Results from the included studies are summarized in Table 2. All studies examined BoNT serotype A. Total doses were variable, ranging from 50 to $400 \mathrm{U}$ (Botox) or 400 to $2360 \mathrm{U}$ (Dysport). Follow-up post injection varied from 14 days to 6 months between studies. Two of the pre-post studies had only a portion of participants with SCI: Opara et al. ${ }^{27}$ also included multiple sclerosis participants, and Beseler et al. ${ }^{28}$ included stroke and brain injury participants. One case series ${ }^{31}$ also included stroke patients. Only results that pertained to the participants with SCI are described in this review.

All studies ${ }^{27,28,30-33}$ measuring MAS reported a decrease in at least one point in response to BoNT. Most studies ${ }^{26-29,31,33}$ also reported an improvement in functional outcome measures in the ICF activity domain. However, an improvement in MAS was not always associated with improvement in function; 8 of the 19 participants in the case series by Hecht et al. ${ }^{30}$ discontinued BoNT injections for this reason. A majority of the participants perceived noticeable reduction in spasticity. However, only participants with a relevant global subjective improvement decided to continue the injections.

The small $(n=28)$ retrospective chart review by Marciniak et al. ${ }^{29}$ reported no differences in improvement between the AISA Impairment Scale (AIS) A versus B,C or D (40\% versus $70 \%, P=0.315$ ), injection within $\leqslant 1$ year of SCI versus $>1$ year $(60 \%$ versus $65 \%$, $P=1.000)$ or injection to upper versus lower limb (65\% versus $64 \%$, $P=1.000)$.

\section{Adverse events with BoNT injections}

Four ${ }^{28,29,33,34}$ of the nine studies did not report on adverse events. Bernuz et al. ${ }^{26}$ reported that $3 / 15$ participants had subsequent hip flexion weakness after injection of rectus femoris, despite no weakness in the knee extensors. Whether the weakness affected walking ability was not reported, and there was no subanalysis for whether outcomes were worse for these affected individuals. Duration of weakness was not reported. Hecht et al. ${ }^{30}$ reported $3 / 19$ cases of transient lower extremity muscle weakness but also did not report duration of weakness or impact on functional abilities. Hecht et al. ${ }^{30}$ also reported $1 / 19$ cases of localized muscle pain post injection with elevated CK, with subsequent investigations demonstrating peripheral neuropathy and myopathy. The authors felt these findings were independent of the injection.

\section{Levels of evidence, BoNT}

There is level 4 and level 5 evidence, based on three pre-post studies, ${ }^{26-28}$ one retrospective chart review ${ }^{29}$ and five case series/ studies, ${ }^{30-34}$ that BoNT has variable effects on lower limb spasticity in SCI. Generally, there were improvements in outcomes measures that looked at body structure and function (for example, MAS), as well as activities (for example, gait). However, an improvement in MAS of at least one point did not necessarily translate to an improvement in activities or subjective global improvement. There is level 5 evidence that BoNT may improve upper limb function in individuals with spasticity from $\mathrm{SCI}^{29}$ and that there is no difference in outcomes between individuals with AIS A versus AIS B-D, whether injections are performed $\leqslant 1$ year versus $\geqslant 1$ year post injury, or to the upper versus lower limbs. ${ }^{29}$ However, small sample sizes and high risk of bias limit firm conclusions, and it is clear that further research is required to confirm the benefits of BoNT as a treatment for spasticity in individuals with SCI.

\section{Chemodenervation with phenol/alcohol}

Phenol and ethanol mediate their effect through direct neurolysis of the nerves that supply spastic muscles. Injection of these agents into the area of a nerve causes denaturation and fibrosis, which disrupts neural transmission and therefore may diminish reflex arcs that are responsible for muscle hypereflexivity. ${ }^{2}$ The duration of effect is highly variable, but it is thought that a degree of permanent denervation occurs with every injection. The effects of phenol/alcohol on 


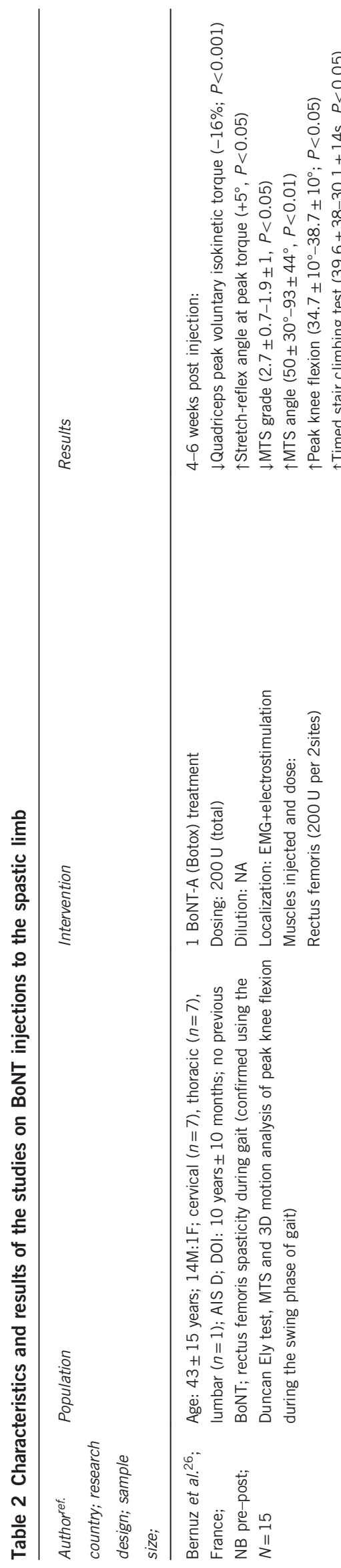




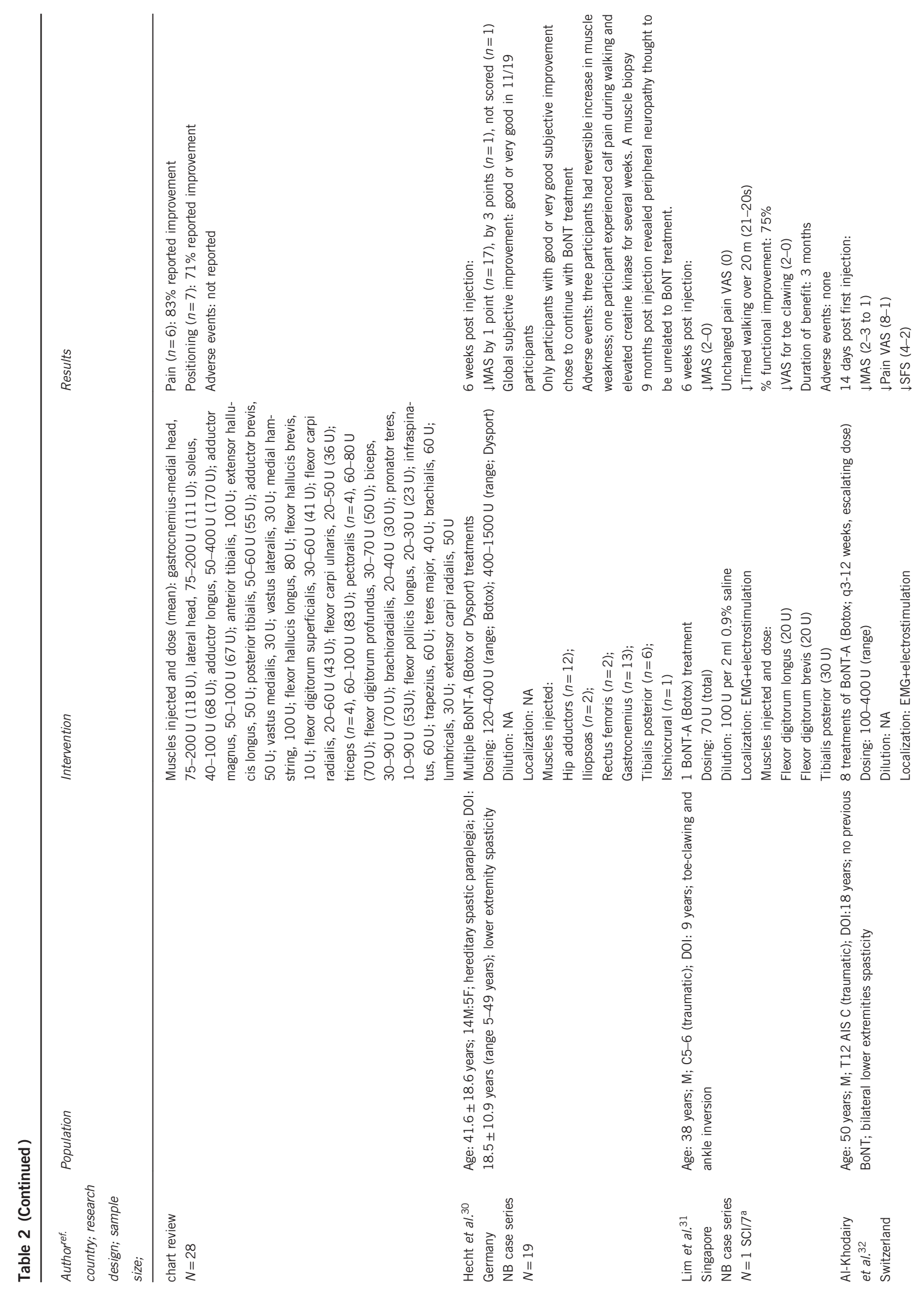




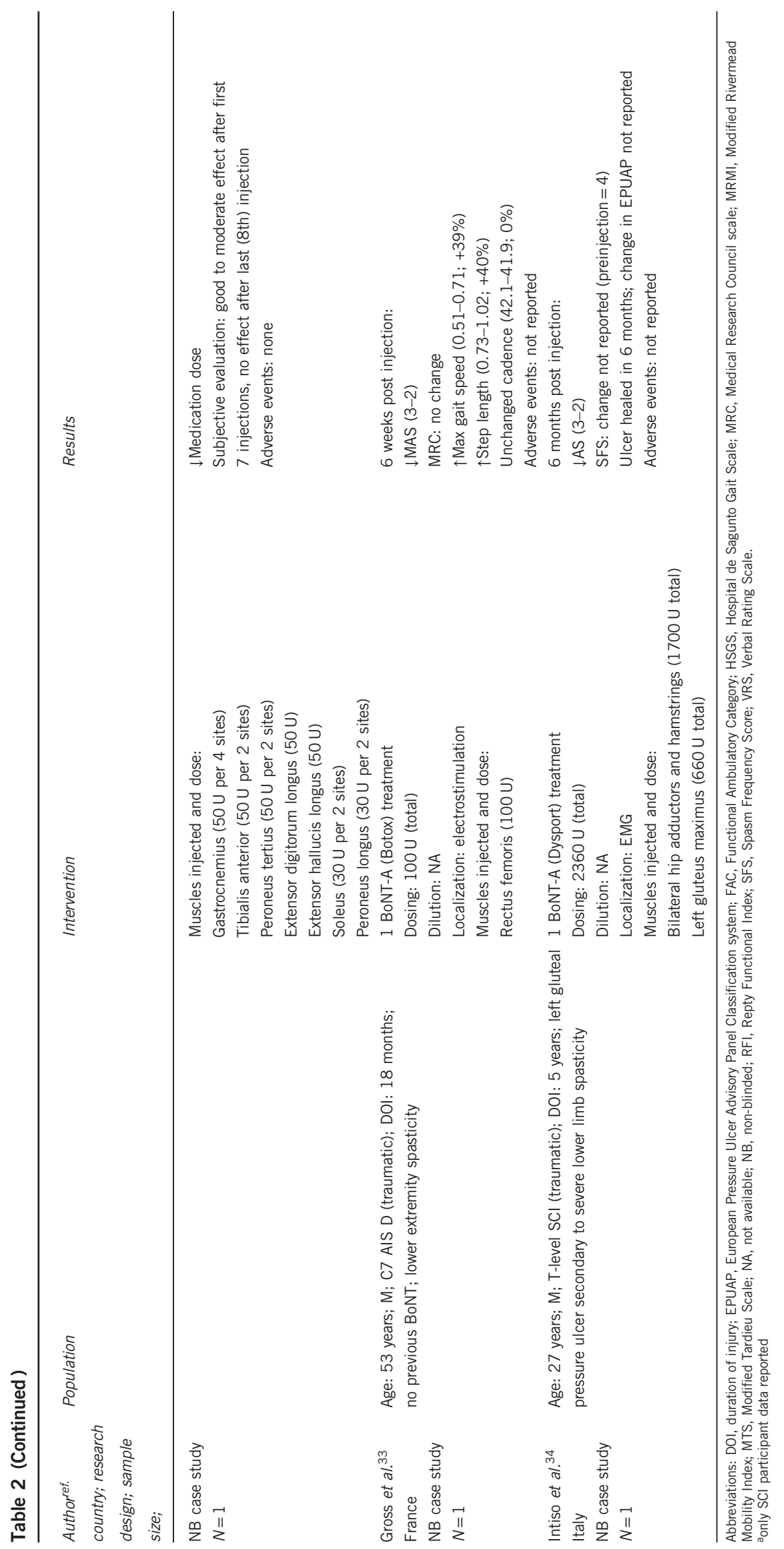




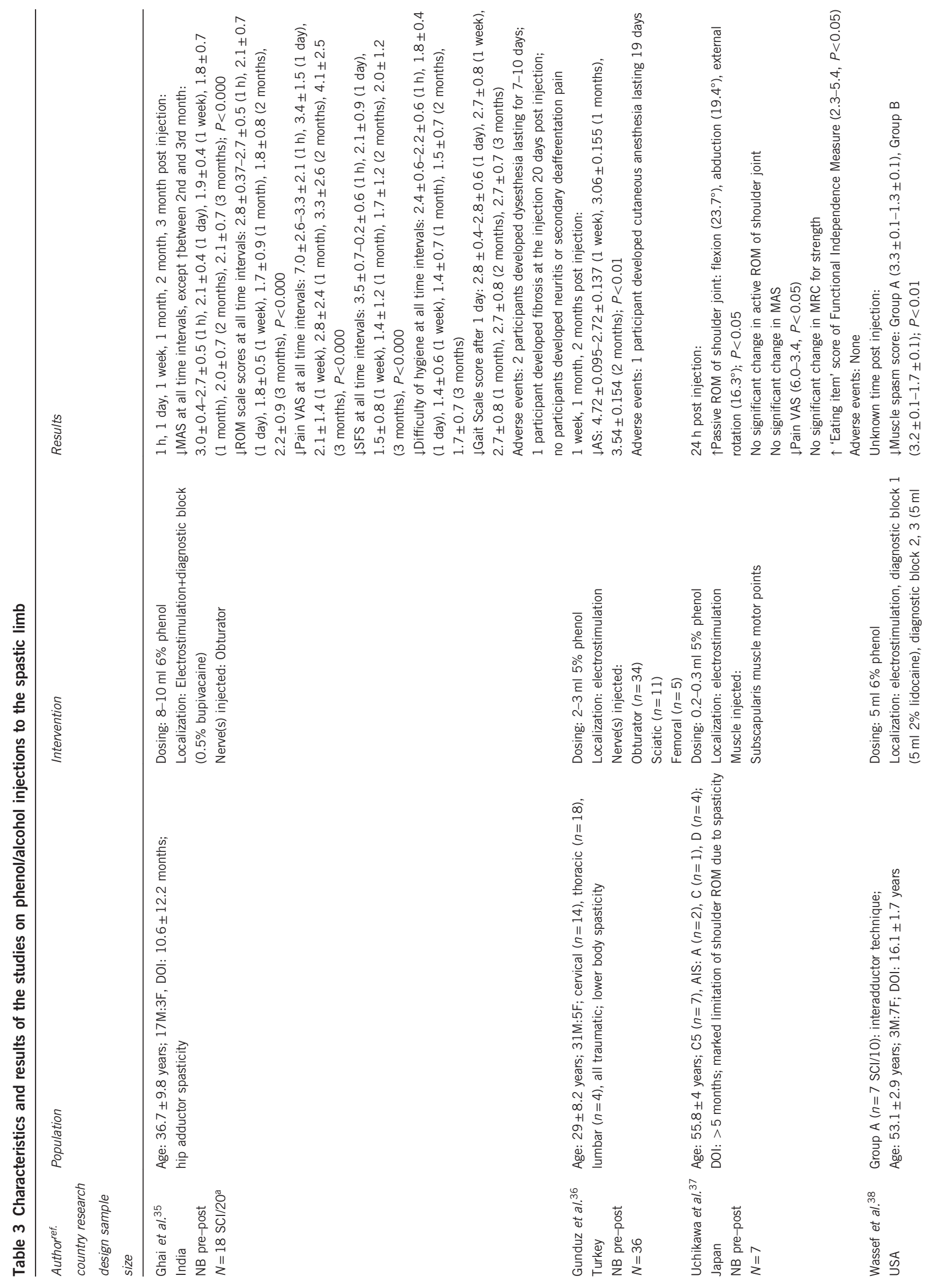




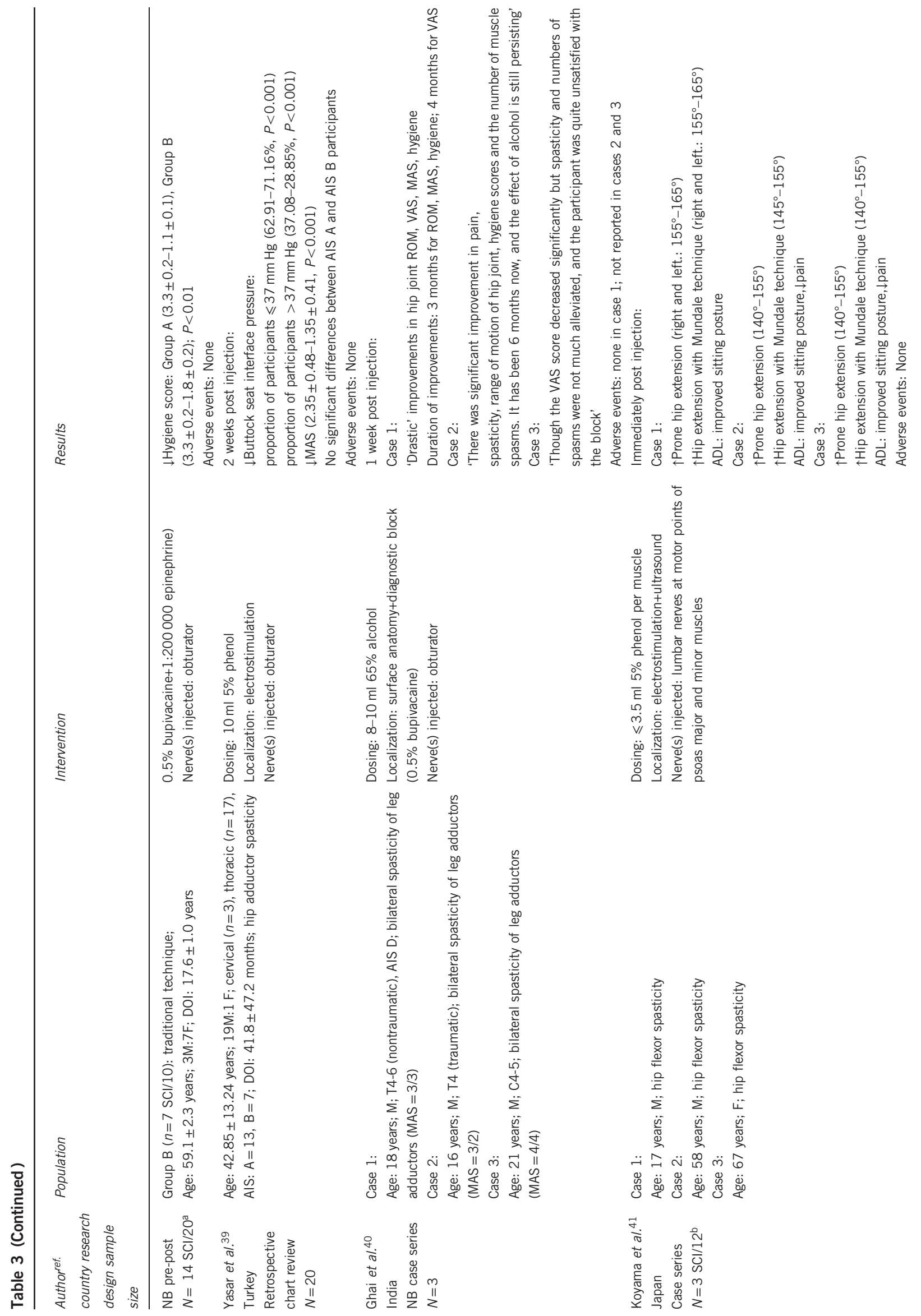




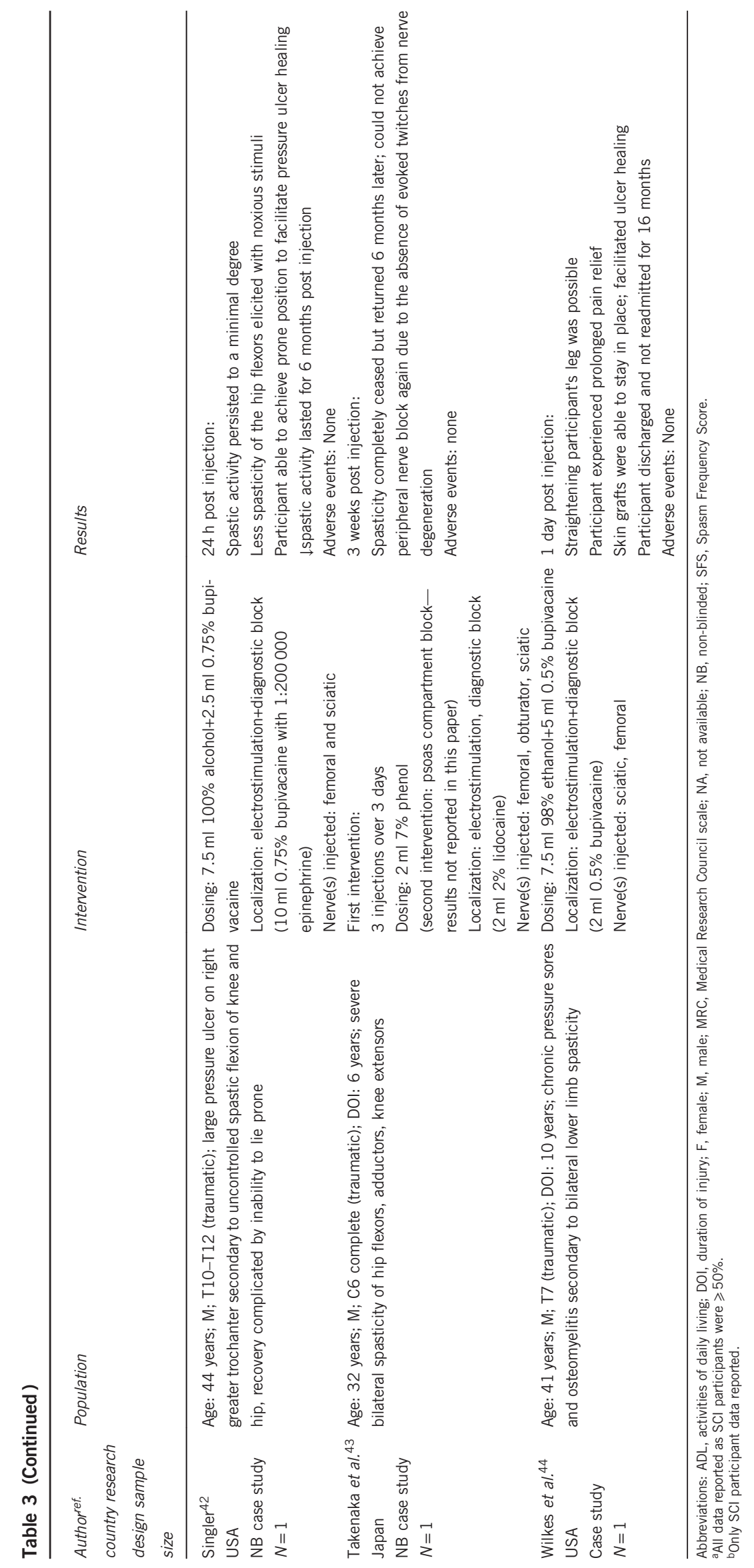




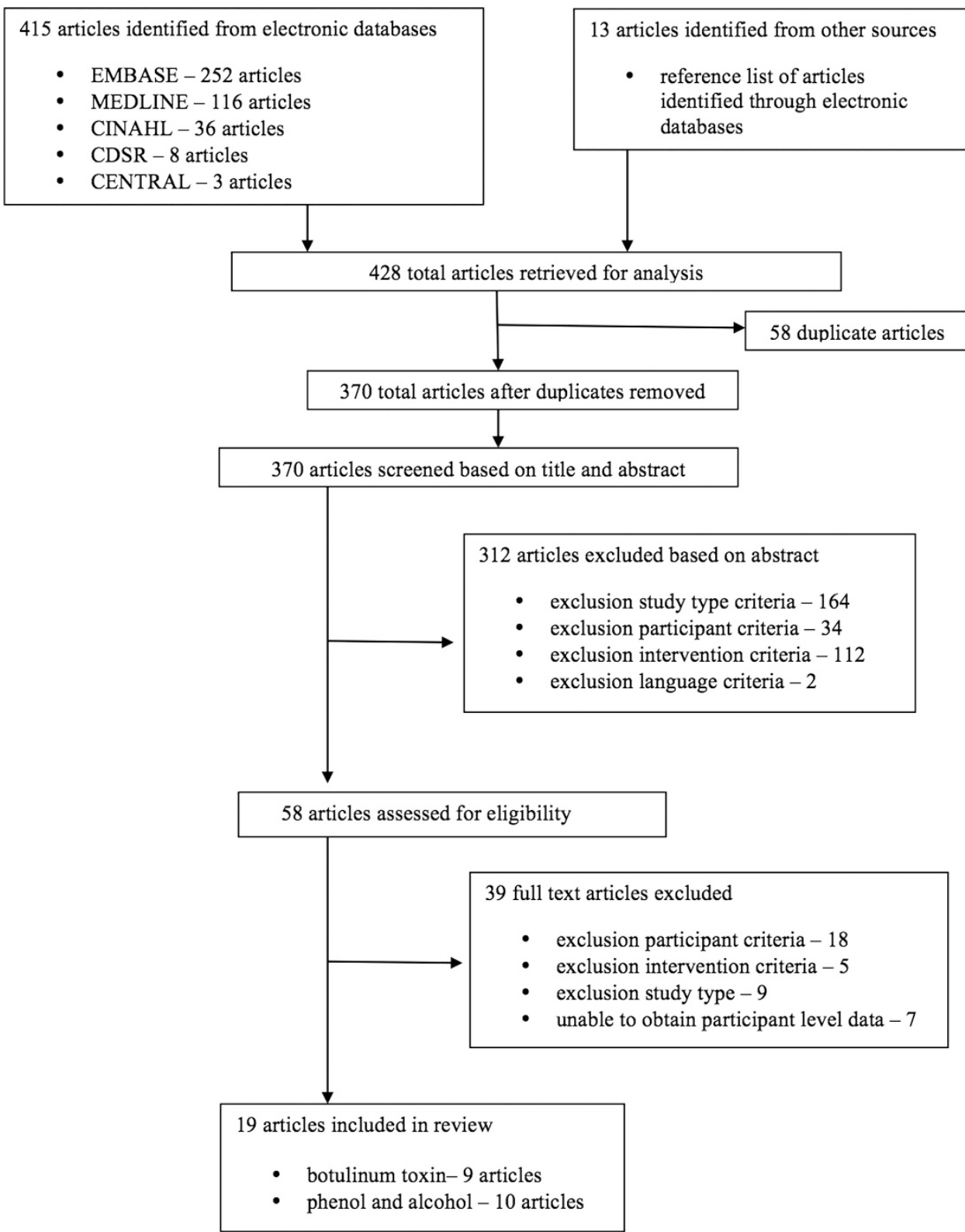

Figure 1 Studies selection flowchart. CDSR, Cochrane Database of Systematic Reviews; CENTRAL, Cochrane Central Register of Controlled Trials.

individuals with SCI have been reported in four level 4 pre-post studies $^{35-38}$ and six level 5 studies (5 case series/studies, ${ }^{40-44}$ one retrospective chart review $^{39}$ ). Results from these studies are summarized in Table 3.

Seven ${ }^{35-39,41,43}$ of the 10 studies involved phenol injections ranging from 0.3 to $10 \mathrm{ml}$ and 5 to $6 \%$ concentration. Alcohol concentration used in three case series/studies ${ }^{40,42,44}$ ranged from 68 to $100 \%$, with volumes between 7.5 and $10 \mathrm{ml}$. Uchikawa et al. ${ }^{37}$ injected subscapularis motor points and Koyama et al. ${ }^{41}$ injected motor points of the psoas muscle. All other studies targeted peripheral nerves in the lower extremities for neurolysis.

Studies by Ghai et $a l .{ }^{35}$ and Wassef et al. ${ }^{38}$ included participants with non-SCI spasticity. As SCI participants comprised $\geqslant 50 \%$ of the samples, and we were unable to obtain patient level data, data pertaining to the entire subject group were included.
Ghai et al., ${ }^{35}$ Yasar et al. ${ }^{39}$ and Uchikawa et al. ${ }^{37}$ used MAS as a primary outcome measure, otherwise selection of outcome measures was variable between studies. The three case studies ${ }^{42-44}$ did not report formal outcome measures and instead provided qualitative descriptions.

Timing of assessments post injection varied from $1 \mathrm{~h}$ to 3 months between studies. Duration of improvement lasted 6 months in the study by Takenaka et al., ${ }^{43} 3-4$ months in Singler et al., ${ }^{42}$ and 6 months in Ghai et al., ${ }^{40}$ depending on the outcome measure. All other studies did not comment on the duration of improvement, although benefits were still present at 2 months in Gunduz et al. ${ }^{36}$ and 3 months in Ghai et al. ${ }^{35}$ Wassef et al. ${ }^{38}$ used two different techniques to target the obturator nerve (interadductor versus traditional technique) and found no differences between the two approaches. 
Overall there were improvements in outcome measurements of body structure and function such as MAS and pain visual analogue scale (VAS) in trials of injections to the lower extremities. The only study looking at spasticity of the upper extremity by Uchikawa et al. found improvements in passive range of motion and pain VAS without an improvement in MAS following phenol to subscapularis motor points. Studies looking at outcome measurements of activity consistently found improvements. Ghai et al. ${ }^{35,40}$ and Wassef et al..$^{38}$ reported improved hygiene score, which measured the ability of nursing staff to access the perineal area. Ghai et al. ${ }^{35}$ also reported an improved gait score after neurolysis as measured by the gait scale $(0=$ able to walk without difficulty, $3=$ unable to walk $)$ in three ambulatory participants, although whether these participants had SCI was not reported. Inspection of gait after the injection revealed decreased scissoring of hips, improved balance and gait speed. All of them, however, still needed assistive devices for ambulation. Uchikawa et $a .^{37}$ measured shoulder function with the 'eating item' of the Functional Independence Measure and reported a significant improvement following phenol injection.

\section{Adverse events with phenol/alcohol injections}

In Ghai et al., ${ }^{35}$ 2/20 participants developed cutaneous dysesthesia, which lasted seven to ten days after the injection. One participant also developed fibrosis at the site of the injection 20 days post injection. It was reported that no participants developed neuritis or secondary deafferentation pain. Gunduz et al. ${ }^{36}$ reported that $1 / 36$ participant developed cutaneous dysesthesia lasting 19 days. Ghai et al. ${ }^{40}$ did not report adverse events for two of the three participants.

\section{Levels of evidence, phenol/alcohol}

There is level 4 and 5 evidence from four pre-post studies, ${ }^{35-38}$ one retrospective chart review ${ }^{39}$ and four case series/studies ${ }^{40,41,43,44}$ that chemodenervation with phenol/alcohol improves limb spasticity as measured by outcomes of body structure and function (for example, MAS, AS, pain visual analogue scale and range of motion). There is level 5 evidence from a retrospective chart review $^{39}$ that phenol neurolysis of obturator nerves improves buttock seat interface pressures, which would presumably decrease the risk of pressure ulcers, in individuals with hip adductor spasticity from SCI. There is level 4 evidence (two pre-post studies ${ }^{35,38}$ ) and level 5 evidence (one case series ${ }^{40}$ ) of decreased difficulty with hygiene performed in the perineal area after phenol neurolysis of the obturator nerves in individuals with adductor spasticity from SCI. There is level 4 evidence from one pre-post study ${ }^{35}$ of improved gait after phenol injection into the obturator nerves, although it is not known whether the three ambulatory participants had SCI versus multiple sclerosis or Koch's spine. There is level 4 evidence from one pre-post study ${ }^{37}$ with $\geqslant 50 \%$ participants with SCI that phenol into the subscapularis motor points improves the 'eating item' score as measured by the Functional Independence Measure. Given the limited number of studies, the small sample sizes and the fact that two out of the four pre-post studies included subjects with etiologies other than SCI, further research is required to determine whether chemodenervation with phenol/alcohol is a safe and effective intervention for the management of spasticity in SCI.

\section{DISCUSSION}

Our systematic review of the literature on chemodenervation for the management of spasticity in SCI found nine studies on BoNT and 10 studies on alcohol/phenol. These were of low quality, with small sample sizes. The existing literature on BoNT is also limited by incomplete descriptions of the intervention, such as dilution used and a lack of reporting of adverse of events. Currently, both BoNT and alcohol/phenol are used clinically in the SCI population to manage limb spasticity; however, these interventions have not been rigorously studied in individuals with SCI.

Chemodenervation has the potential to be a useful tool in treating focal limb spasticity after SCI, but there may also be significant side effects with both BoNT and phenol/alcohol, including the potential to worsen functional abilities. The pre-post studies by Ghai et al. ${ }^{35}$ (phenol injection) and Bernuz et al. ${ }^{26}$ (BoNT injection) examined chemodenervation of proximal muscles in the leg (hip adductors and knee extensors, respectively) in ambulatory participants. This represents a challenging clinical scenario, as it is difficult to compensate for excessive weakening of these more proximal muscles, unlike the use of an ankle-foot orthosis to compensate for weakness of the ankle dorsi/plantar flexors post injection. Therefore, there is a concern that chemodenervation of hip and knee stabilizers could lead to a worsening of gait, which can significantly impact the individual's functioning and quality of life for what could be a prolonged period of time. The study by Bernuz et al. ${ }^{26}$ injected $200 \mathrm{U}$ of BoNT into the rectus femoris, an important muscle for stabilizing the knee during stance phase. A mean improvement in gait parameters and stair climbing was reported, despite subsequent hip flexion but not knee extension weakness in three participants. However, there was no subanalysis on whether outcomes were worse in these affected participants. The authors' recommendation was to avoid injections into the rectus femoris in individuals with hip flexion strength $\leqslant 2$ on the Medical Research Council scale. Given that these results are based on a small number of participants, further research into this area is necessary to establish whether and in what scenarios the benefits of BoNT injection into the rectus femoris for stiff-knee gait outweigh the risk of negatively impacting ambulation.

The study by Ghai et al. ${ }^{35}$ also had only three participants who were ambulatory, and they found an improved gait scale score after obturator neurolysis with phenol for adductor spasticity. Their population of 20 included two participants with multiple sclerosis and two with Koch's spine in addition to the 16 with SCI, but they did not describe the etiology of spasticity for the three ambulatory participants. Therefore, it is difficult to determine whether the improved gait scale score is relevant to the SCI population. Further research is also required to determine whether obturator neurolysis is a safe and effective intervention in ambulatory individuals with adductor spasticity from SCI, especially as the effects of phenol have the potential to last beyond 6 months.

\section{Recommendations for future research}

Currently, there is great variability in the choice of outcome measures used in limb spasticity research. The MAS was the outcome measure most commonly used across studies in this review $(n=10)$. The reduction in spasticity of MAS of at least one point did not necessarily translate to an improvement in activities or participant's global subjective improvement, ${ }^{30}$ suggesting that MAS changes without functional changes may not be sufficiently important to continue with chemodenervation. Also, the minimally clinically important difference for the MAS has not been established in the literature. Given that spasticity is known to affect participation and employment ${ }^{6}$ as well as quality of life ${ }^{7}$ in individuals with SCI, researchers should attempt to capture these outcomes in future studies. There is evidence that clinical assessment of spasticity has poor correlation with the general spasticity experience in $\mathrm{SCI} ;^{30,47}$ therefore, subjective, selfreported measures should also be evaluated. Detailed information on 
adverse events, including the duration and impact of muscle weakness on functional abilities, should also be collected, as these results are crucial for clinicians and patients deciding on whether the benefits of chemodenervation outweigh the risks.

Studies should describe in detail the characteristics of the SCI participants including level, completeness and duration of injury. Marciniak et al. ${ }^{29}$ did not find a difference in response between individuals with AIS A versus AIS B-D, nor differences between participants with $\leqslant 1$ versus $>1$ year duration of injury; however, this was a small retrospective chart review. Further research may clarify whether these factors affect outcomes in spasticity management in SCI. In addition, complete description of the intervention including concentration, dosing, muscle selection, muscle or nerve method of localization is crucial, so as to enable comparisons across studies. There is evidence from at least one RCT that BoNT dilution ${ }^{48}$ can affect outcomes. Also, the sole use of anatomical landmarks has been shown to be inferior to electromyography plus anatomy for muscle localization, ${ }^{49}$ therefore should be avoided when possible both in the research and clinical setting.

Finally, there are questions regarding the cost-effectiveness of using BoNT in chemodenervation. A recent Health Technology Assessment report suggested that BoNT treatment of upper limb spasticity in stroke is not cost-effective given the high cost of the drug and limited functional improvements observed. ${ }^{50}$ Future studies should include a similar economic evaluation on BoNT and SCI spasticity. Given the large difference in cost between BoNT and phenol/alcohol, a costeffectiveness analysis between the agents may be warranted.

\section{Study limitations}

The strength of our findings is limited by the inclusion of small, low-quality studies and the inability to meta-analyze results due to heterogeneity of study methods. This paper has tried to take these factors into account by assessing risk of bias and assignation of levels of evidence. Articles reviewed were limited to English and, although the search strategy to identify studies for this review was comprehensive, given the broad nature of the topic reviewed, it is possible that some studies may have been missed.

\section{CONCLUSION}

A small number of studies with low levels of evidence were found examining the use of chemodenervation with BoNT or phenol/alcohol for management of limb spasticity in SCI. These results highlight the need for additional evaluations and more complete reporting of interventions and outcomes including adverse events to help guide clinicians treating individuals with limb spasticity from SCI. As the patterns of spasticity seen in SCI can differ compared with those with other etiologies of spasticity, there is a need for research specific to the SCI population. Areas of priority include establishing a consensus on what outcome measures should be used and exploration of potential factors (for example, type and duration of injury) that can affect outcomes with spasticity management in SCI.

\section{CONFLICT OF INTEREST}

The authors declare no conflict of interest.

\section{ACKNOWLEDGEMENTS}

Jordon Lui received funding from the UBC Faculty of Medicine Summer Student Research Program during the conduction of this review. Dr Patricia Mills receives research salary support from the Vancouver Coastal Health Research Institute, TD Grants in Medical Excellence and VGH \& UBC Hospital
Foundation. We thank Dr Janice Eng and Dr Heather Finlayson for editorial assistance.

1 Lance JW. The control of muscle tone, reflexes, and movement: Robert Wartenbeg Lecture. Neurology 1980; 30: 1303-1303.

2 Adams MM, Hicks AL. Spasticity after spinal cord injury. Spinal Cord 2005; 43 : 577-586.

3 Walter JS, Sacks J, Othman R, Rankin AZ, Nemchausky B, Chintam R et al. A database of self-reported secondary medical problems among VA spinal cord injury patients: its role in clinical care and management. J Rehabil Res Dev 2002; 39: 53-61.

4 Levi R, Hultling C, Seiger A. The Stockholm Spinal Cord Injury Study: 2. Associations between clinical patient characteristics and post-acute medical problems. Paraplegia 1995; 33: 585-594.

5 Johnson RL, Gerhart KA, McCray J, Menconi JC, Whiteneck GG. Secondary conditions following spinal cord injury in a population-based sample. Spinal Cord 1998; 36: 45-50.

6 Anderson CJ, Vogel LC. Employment outcomes of adults who sustained spinal cord injuries as children or adolescents. Arch Phys Med Rehabil 2002; 83: 791-801.

7 Westerkam D, Saunders LL, Krause JS. Association of spasticity and life satisfaction after spinal cord injury. Spinal Cord 2011; 49: 990-994.

8 Elovic E. Principles of pharmaceutical management of spastic hypertonia. Phys Med Rehabil Clin N Am 2001; 12: 793-816.

9 Ward AB. Spasticity treatment with botulinum toxins. J Neural Transm 2008; 115 : 607-616.

10 Elovic EP, Esquenazi A, Alter KE, Lin JL, Alfaro A, Kaelin DL. Chemodenervation and nerve blocks in the diagnosis and management of spasticity and muscle overactivity. PM R 2009; 1: 842-851.

11 Halpern D, Meelhuysen FE. Phenol motor point block in the management of muscular hypertonia. Arch Phys Med Rehabil 1966; 47: 659-664.

12 Elia AE, Filippini G, Calandrella D, Albanese A. Botulinum neurotoxins for post-stroke spasticity in adults: a systematic review. Mov Disord 2009; 24: 801-812.

13 Foley N, Pereira S, Salter K, Fernandez MM, Speechley M, Sequeira K et al. Treatment with botulinum toxin improves upper-extremity function post stroke: a systematic review and meta-analysis. Arch Phys Med Rehabil 2013; 94: 977-989.

14 Ade-Hall RA, Moore AP. Botulinum toxin type A in the treatment of lower limb spasticity in cerebral palsy. Cochrane database Syst Rev 2000, CD001408.

15 Boyd RN, Morris ME, Graham HK. Management of upper limb dysfunction in children with cerebral palsy: a systematic review. Eur J Neurol 2001; 8: 150-166.

16 Sheean GL. Botulinum treatment of spasticity: why is it so difficult to show a functional benefit? Curr Opin Neurol 2001; 14: 771-776.

17 Mukherjee A, Chakravarty A. Spasticity mechanisms-for the clinician. Front Neurol 2010; 1: 149.

18 Ohn SH, Yoo W-K, Kim DY, Ahn S, Jung B, Choi I et al. Measurement of synergy and spasticity during functional movement of the post-stoke hemiplegic upper limb. J Electromyogr Kinesiol 2013; 23: 501-507.

19 Little JW, Micklesen P, Umlauf R, Britell C. Lower extremity manifestations of spasticity in chronic spinal cord injury. Am J Phys Med Rehabil 1989; 68: 32-36.

20 Moseley AM, Herbert RD, Sherrington C, Maher CG. Evidence for physiotherapy practice: a survey of the Physiotherapy Evidence Database (PEDro). Aust J Physiother 2002; 48: 43-49.

21 Downs SH, Black N. The feasibility of creating a checklist for the assessment of the methodological quality both of randomised and non-randomised studies of health care interventions. J Epidemiol Community Health 1998; 52: 377-384.

22 Sackett DL, Rosenberg WM, Gray JA, Haynes RB, Richardson WS. Evidence based medicine: what it is and what it isn't. BMJ 1996; 312: 71-72.

23 Eng J, Teasell R, Miller W, Wolfe D, Townson A, Aubut J-A et al. Spinal cord injury rehabilitation evidence: method of the scire systematic review. Top Spinal Cord Inj Rehabil 2007; 13: 1-10.

24 Higgins JPT, Green S Cochrane Handbook for Systematic Reviews of Interventions Version 5.1.0 [updated March 2011], 2011.

25 Organization WH. WHO I International Classification of Functioning, Disability and Health (ICF). http://www.who.int/classifications/icf/icf_more/en/ (accessed 27 Mar 2014).

26 Bernuz B, Genet F, Terrat P, Pradon D, Barbot F, Bussel B et al. Botulinum toxin effect on voluntary and stretch reflex-related torque produced by the quadriceps: an isokinetic pilot study. Neurorehabil Neural Repair 2012; 26: 542-547.

27 Opara J, Hordynska E, Swoboda A. Effectiveness of botulinum toxin A in the treatment of spasticity of the lower extremities in adults-preliminary report. Ortop Traumatol Rehabil 2007; 9: 277-285.

28 Beseler MR, Grao CM, Gil A, Martinez Lozano MD. Walking assessment with instrumented insoles in patients with lower limb spasticity after botulinum toxin infiltration. Neurologia 2012; 27: 519-530.

29 Marciniak C, Rader L, Gagnon C. The use of botulinum toxin for spasticity after spinal cord injury. Am J Phys Med Rehabil 2008; 87: 312-329.

30 Hecht MJ, Stolze H, Auf dem Brinke M, Giess R, Treig T, Winterholler M et al. Botulinum neurotoxin type $A$ injections reduce spasticity in mild to moderate hereditary spastic paraplegia-report of 19 cases. Mov Disord 2008; 23: 228-233.

$31 \mathrm{Lim}$ ECH, Ong BKC, Seet RCS. Botulinum toxin-A injections for spastic toe clawing. Parkinsonism Relat Disord 2006; 12: 43-47. 
32 Al-Khodairy AT, Gobelet C, Rossier AB. Has botulinum toxin type A a place in the treatment of spasticity in spinal cord injury patients? Spinal Cord 1998; 36: 854-858.

33 Gross R, Leboeuf F, Remy-Neris O, Perrouin-Verbe B. Unstable gait due to spasticity of the rectus femoris: gait analysis and motor nerve block. Ann Phys Rehabil Med 2012 55: 609-622.

34 Intiso D, Basciani M. Botulinum toxin type A in the healing of a chronic buttock ulcer in a patient with spastic paraplegia after spinal cord injury. J Rehabil Med 2009; 41: 1100-1102.

35 Ghai A, Sangwan SS, Hooda S, Garg N, Kundu ZS, Gupta T. Evaluation of interadductor approach in neurolytic blockade of obturator nerve in spastic patients. Saudi J Anaesth 2013; 7: 420-426.

36 Gunduz S, Kalyon TA, Dursun H, Mohur H, Bilgic F. Peripheral nerve block with phenol to treat spasticity in spinal cord injured patients. Paraplegia 1992; 30: 808-811.

37 Uchikawa K, Toikawa H, Liu M. Subscapularis motor point block for spastic shoulders in patients with cervical cord injury. Spinal Cord 2009; 47: 249-251.

38 Wassef MR. Interadductor approach to obturator nerve blockade for spastic conditions of adductor thigh muscles. Reg Anesth 1993; 18: 13-17.

39 Yaşar E, Tok F, Taşkaynatan MA, Yilmaz B, Balaban B, Alaca R. The effects of phenol neurolysis of the obturator nerve on the distribution of buttock-seat interface pressure in spinal cord injury patients with hip adductor spasticity. Spinal Cord 2010; 48 828-831.

40 Ghai A, Sangwan SS, Hooda S, Kiran S, Garg N. Obturator neurolysis using 65\% alcohol for adductor muscle spasticity. Saudi J Anaesth 2012; 6: 282-284.

41 Koyama H, Murakami K, Suzuki T, Suzaki K. Phenol block for hip flexor muscle spasticity under ultrasonic monitoring. Arch Phys Med Rehabil 1992; 73 1040-1043.

42 Singler RC. Alcohol neurolysis of sciatic and femoral nerves. Anesth Analg 1981; 60 532-533.

43 Takenaka M, lida H, Ohta S, Dohi S. Psoas compartment block for the treatment of lower-limb spasticity caused by spinal cord injury: Report of a case. J Anesth 1997; 11: 300-302.

44 Wilkes D, Ganceres N, Doulatram G, Solanki D. Alcohol neurolysis of the sciatic and femoral nerves to improve pressure ulcer healing. Pain Pract 2009; 9: 145-149.

45 Richardson D, Sheean G, Werring D, Desai M, Edwards S, Greenwood R et al. Evaluating the role of botulinum toxin in the management of focal hypertonia in adults. J Neurol Neurosurg Psychiatry 2000; 69: 499-506.

46 Barnes M. Botulinum toxin - mechanisms of action and clinical use in spasticity. J Rehabil Med 2003; 35: 56-59.

47 Lechner H, Frotzler A, Eser P. Relationship between self- and clinically rated spasticity in spinal cord injury. Arch Phys Med Rehabil 2006; 87: 15-19.

48 Gracies J-M, Lugassy M, Weisz DJ, Vecchio M, Flanagan S, Simpson DM. Botulinum toxin dilution and endplate targeting in spasticity: a double-blind controlled study. Arch Phys Med Rehabil 2009; 90: 9-16.e2.

49 Ploumis A, Varvarousis D, Konitsiotis S, Beris A. Effectiveness of botulinum toxin injection with and without needle electromyographic guidance for the treatment of spasticity in hemiplegic patients: a randomized controlled trial. Disabil Rehabil 2014; 36: 313-318.

50 Shaw L, Rodgers $H$, Price $C$, van Wijck F, Shackley $P$, Steen $N$ et al. BoTULS: a multicentre randomised controlled trial to evaluate the clinical effectiveness and cost-effectiveness of treating upper limb spasticity due to stroke with botulinum toxin type A. Health Technol Assess 2010; 14: 1-113.

\section{APPENDIX}

MEDLINE search strategy
1. Spinal cord injuries/
2. Paraplegia/
3. Brown sequard syndrome/
4. Quadriplegia/
5. Central Cord Syndrome/
6. (spinal cord adj5 (trauma or transection or laceration or contusion)).mp.
7. (traumatic adj3 myelopathy).mp.
8. (spinal cord adj5 injur\$).mp.
9. (paralysis adj3 (lower extremit\$ or leg\$ or lower limb\$)).mp.
10. (quadripleg $\$$ or tetrapleg $\$$ or parapleg $\$$ ).mp.
11. (paraplegia adj3 (spinal or spastic)).mp.
12. or/1-11
13. Exp Muscle Spasticity/
14. ((muscle* or muscular) adj3 (spasm* or cramp* or spastic* or clonus)).ab,ti.
15. spasticit*.mp
16. or/13-15
17. exp Phenols/
18. exp Denervation/
19. exp Alcohols/
20. exp Ethanol/
21. exp Botulinum Toxins/
22. or/17-21
23. 12 and 16 and 22
24. Limit 23 to humans
25. Limit 24 to English language 